\title{
The Sonoristic Triangle, Or, What Claude Lévi- Strauss Would Have Said About Sound Culture If He Had Not Talked About Cooking Instead
}

\author{
Dariusz Brzostek \\ Faculty of Languages \\ Nicolaus Copernicus University in Torun \\ darek_b@umk.pl \\ Received 6 May 2017; accepted 29 May 2017. \\ Translation: Izabela Dąbrowska
}

\begin{abstract}
The aim of this article is cultural analysis of modern and postmodern sound culture, based on a structuralist description of the differences between acoustic (traditional), electroacoustic (modern) and electronic (postmodern) sound. The analytical model applied in this study is the so-called "culinary triangle" proposed by Claude Lévi-Strauss and modified here to a "sonoristic triangle" which describes the transition of culture from modernity to postmodernity.
\end{abstract}

Keywords: modernism, postmodernism, sound culture, culinary triangle, structuralism

There is a culinary aspect in every act of speech...

Claude Jaeglé

\section{Food, or the Metaphor}

Claude Lévi-Strauss, the godfather of modern anthropology and founder of structuralist ethnology, used in one of his classic works (Lévi-Strauss, 2008) the concept of the "culinary triangle" to illustrate the structural opposition between what is natural and what is

\footnotetext{
${ }^{1}$ Lévi-Strauss refers in this context to the famous phonetic "vovel triangle."
} 
cultural, and to depict the process of human transition from the state of nature to the state of culture. This concept referred to the three basic categories corresponding to the three states in which food can be: "the raw," "the cooked" and "the rotted." The structural relations among them reflected the fundamental difference between what is unelaborated (and thus "natural”) and what is elaborated (and thus ,cultural”). In this way, food (and its methods of preparation) became a clear metaphor of the process of the acculturation of humanity. Let us consider whether we could successfully build an analogous triangle (to simplify, we will call it "sonoristic"2) which would refer to the relations of man with the surrounding world of sounds. We begin with a slightly risky paraphrase of the great anthropologist's memorable words:

We will start from the hypothesis that working with sound presupposes a system which is located - according to different variations of the art of sound in the particular cultures one wants to consider - within a triangular semantic field whose three points correspond respectively to the categories of the "natural", the "artistic" and the "noisy." It is clear that in respect to sound art the natural constitutes the unmarked pole while the other two poles are strongly marked, but in different directions: indeed, the artistic is a cultural transformation of the natural whereas the noisy is a natural transformation. Underlying our original triangle, there is hence a double opposition between elaborated/unelaborated on the one hand, and culture/nature on the other. (Lévi-Strauss, 2008, pp. 37-38)

This paraphrase is based on quite an extravagant analogy, pairing cooking (culinary practice) with music (the art of sound), understood here very broadly in the categories of late modernity and also as sound art, i.e., the cultural practice of working with sound, not necessarily in a musical way. Very careful reading is not necessary to point out that the above paraphrase reveals the inconsequence and naivety of this simplifying analogy. While artistic sounds do actually turn out to be a "cultural transformation of the natural," noisy sounds are by no means its natural transformation; on the contrary, they turn out to be another version of cultural transformation of natural sounds, or even aesthetically undesirable products of culture itself. Very infrequently, they belong to the sphere of natural phenomena; as we can read in the classic writings on modern aesthetics, nature does make noise - the howling of wind, the rolling of thunder, the roar of surf - in a way that is at least sublime. Unlike the culinary triangle, the sonoristic triangle thus created delineates neither the clear opposition between the elaborated and the unelaborated nor an even clearer one between culture and nature. One may of course easily imagine a different sonoristic triangle, formed on the basis of the categories of the natural, the communicative and the nonsensical, which will incisively realize the opposition of nature vs. culture. However, it would limit the sphere of working with sound to the sounds of speech, which additionally would be a repetition of the French anthropologist's statement regarding the

\footnotetext{
${ }^{2}$ Here I use the term "sonoristic" not as a reference to the particular composition practices of the $20^{\text {th }}$ century avant-garde (sonorism) but in the context of broader strategies of experimental work with sound which take "the form of a test of the material itself" (Schaeffer, 1987, p. 106). They dominated the various tendencies of the modern sound art-from musique concrète to the practice of sound installations and sound studies. Thus it is one of the key concepts in understanding the modern sound culture.
} 
universal character of this structural opposition. Yet, does the failure of this simple thought experiment mean that the famous concept of Claude Lévi-Strauss is unable to divulge anything regarding the culture of sound? Not necessarily.

As we remember, in his deliberations Lévi-Strauss returns to the culinary triangle, but now it refers to the specific culinary practices followed in a given culture, making a reservation that "[w]ithin it we traced another triangle representing recipes, at least the most elementary ones: roasting, boiling and smoking (Lévi-Strauss, 2008, p. 42). As it considers fire as a culture-making factor and includes mediating elements (air, water) as well as specific techniques of making food (frying, braising etc.), this scheme allows us, according to the French anthropologist, "to discover for each specific case how the cooking of a society is a language in which it unconsciously translates its structure" (Lévi-Strauss, 2008, p. 43). Let us follow this trail in an attempt to discover certain (elementary?) mechanisms of "sound management" in culture; however, an initial reservation ought to be made: We may wonder whether using sounds is as essential for human existence as gathering and processing food. Consequently, producing this sound culture does not necessarily have to be located at the fundamental level of human experience of the world and therefore produce the structural difference between nature and culture. However, in my opinion the sonoristic triangle can be successfully used to differentiate individual cultural formations within a culture (e.g., in the process of their civilizational development). I suggest the following speculation: preserving the basic opposition between the natural and the elaborated, we should place this triangle not on the axis of nature vs. culture, but on the axis of modernism vs. postmodernism, adequate to the characteristics of Western culture at the turn of the $20^{\text {th }}$ and the $21^{\text {st }}$ centuries. The sonoristic triangle itself would ultimately take the form of the acoustic - the electroacoustic - the electronic, where the acoustic would fall on the side of the natural, while the electroacoustic and the electronic would be in the sphere of the elaborated. At the same time, the electroacoustic would represent in this scheme the modernist order while the electronic would reflect the domain of the postmodern. Succumbing here to the magic of graphs and diagrams, which seduced both LéviStrauss and Jacques Lacan, not to mention a veritable throng of minor structuralists, I present it in this way:

\section{ACOUSTIC}

natural

$(+)$

instrument

ELECTROACOUSTIC

prepared

(modernism)
$(-)$

instrument

ELECTRONIC

prepared

(postmodernism) 
The scheme contains one more concept which requires specification, i.e., an "instrument," understood here in a traditional (and thus pre-modernist) way as "an acoustic source of (musical) sound." To clarify the argument, I must explain that in my considerations the role of the fire that transforms the sound will obviously be played by electricity.

\section{Modernization and Simulation}

To carry out a deeper analysis of this transformation of sound modernity into postmodernity, we must first stabilize, at least functionally, the very concept of postmodernism. Avoiding the fundamental philosophical disputes on the essence of what „postmodern” is, I will recall only these basic issues of postmodernism which are directly related to the problem that I focus on: processing of sound and music and its relation to the new technologies which transform the very nature of the postmodern reality. In his classic (which is clearly an awkward word in this context) essay "Answering the Question: What Is Postmodernism?", Jean-François Lyotard (1984) connects postmodernism with the essential question about the classically understood realism, "whose only definition is that it intends to avoid the question of reality implicated in that of art" (p. 75). This question in turn is obviously related to the modernist (and bourgeoisie) "demand for reality - that is for unity, simplicity, communicability etc." (p. 75). In Lyotard's approach, this issue is also related to the criticism of capitalism, which ,inherently possesses the power to derealize familiar objects, social roles, and institutions to such a degree that the so-called realistic representations can no longer evoke reality except as nostalgia or mockery, as an occasion for suffering rather than for satisfaction. Classicism seems to be ruled out in a world in which reality is so destabilized that it offers no occasion for experience, but only for ratings and experimentation." (Lyotard, 1984, p. 74). In this context, postmodernism becomes a domain of "unstable reality" which impugns the very mode in which humans experience the world. Consequently, as Lyotard concludes, „The postmodern would be that which, in the modern, puts forward the unpresentable in presentation itself ..." (Lyotard, 1984, p. 81).

In turn, Jean Baudrillard (1988) associates the condition of late modernity with the tendency to simulate (reality): "Abstraction today is no longer that of the map, the double, the mirror or the concept. Simulation is no longer that of a territory, a referential being or a substance. It is the generation by models of a real without origin or reality: a hyperreal" (p. 166). Contemporary technology is specialized in producing simulacra: natural ("based on image, imitation, and counterfeiting"), productive ("materialized by the machine") and simulation simulacra ("based on information, the model, cybernetic play"), whose aim is "total control" (Baudrillard, 1991). From now on the reality "is produced from miniaturized units, from matrices, memory banks and command models - and with these it can be reproduced an indefinite number of times" (Baudrillard, 1988, p. 167). As a result, we face "substituting signs of the real for the real itself; that is, an operation to deter every real process by its operational double, a metastable, programmatic, perfect descriptive machine which provides all the signs of the real..." (Baudrillard, 1988, p. 167). Yet is there any room for generating sound and postmodern electronic music? 
Interestingly, in his important book Postmodernism, Or the Cultural Logic of Late Capitalism, Fredric Jameson (1997) mentions music and sound art only incidentally (e.g., in the context of cinema and its genre hybridity and eclectism), focusing on music only once, but in relation to the question that interests us. "Technologies of the musical, to be sure, whether of production, reproduction, reception, or consumption, already worked to fashion a new sonorous space around the individual or the collective listener: in music, too, "representationality"-in the sense of drawing up your fauteuil and gazing across at the spectacle unfolded before you-has known its crisis and its specific historical disintegration" (p. 298). Thus creating sounds moves into the sphere of simulation.

When analyzing the sound aspect of the transition from modernism to postmodernism, we should also remember that in his writings on the transformations of contemporary music and the related redefinition of the position of an experimenting artist, Bogusław Schaeffer perceptively stated that a modern artistic experiment "should involve the musical substance itself, and undoubtedly working with sound itself . .., working within the material is closest to contemporary experimentation" (Schaeffer, 1987, p. 106). These postulates were to be realized by experimental electronic music and musique concrète ${ }^{3}$. Postmodernism in the culture of sound (and in musical culture) is thus directly connected with the movement from electroacoustics to electronics, that is, with the birth of electronic sound synthesis and the beginnings of musique concrète and Pierre Schaeffer's concept of the sound object, which is the "synthesis of the natural material and the technical method of creation" (Schaeffer, 1987, p. 112). As Rolf Inge Godøy (2008, p. 67) notes, a sound object can be any sound of instrumental, vocal, electronic or environmental origin which is, however, perceived as a cohesive and complete unit, in separation from its actual source. The sound object thus composed acquires in the context of the new musical unity not only the status of musical material, but also that of an acousmatic sound [Fr. acousmate], that is, a sensory hallucination created by a sound from an unknown source (see also Murch, 1994, p. XXI). This happens due to the very essence of a sound object, which resonates (from nowhere or from somewhere else) like something apparently well known yet removed from the sound context that is cognitively familiar, and placed in a new, unexpected one, it may also resonate here and now without any discernible reason. It can also be deceptively similar to the sound of what is familiar, yet it possesses a tiny, discreet flaw (such as resonance or modulation) which makes it unrecognizable, endowing it with the attributes of the uncanny. ${ }^{4}$ An acousmatic sound as an auditory illusion is in an obvious way a simulation of reality. Listening to such sounds corresponds to the "acousmatic situation" described in detail by Pierre Schaeffer (2004, pp. 77-78), which excludes all references to what is visible, tangible and measurable, moving towards surrendering oneself entirely and solely to listening, to discovering instinctual paths leading from what is purely "of sound" to what is purely "of

\footnotetext{
${ }^{3}$ As Bogusław Schaeffer (1987) rightly noticed, "with time musique concrète grew closer to electronic music. This may have been caused by the simple fact that similar or even identical methods work analogously...” (p. 112).

${ }^{4}$ Acousmatic sound is in this context, ,an impossible sound” (see also Brzostek, 2011).
} 
music" (Schaeffer, 2004, p. 81). Clearly the postmodern strategy of creating sound through electronic synthesis has led to a remodeling of the very concept of a musical instrument, producing peculiar "sound phantomatics," as we actually have - instead of the instrument (or rather functioning as an instrument) — a Lemian "phantomatic machine" which serves not (only) music, but (also) phantomatics (virtual reality), that is, the technique creating artificial reality, extremely similar to the natural but impossible to discern from it (Lem, 1984, p. 161); it thus evokes questions both aesthetic and epistemological.

In this context it is worth recollecting two examples from the history of the most recent music which will adequately illustrate this transition from instrumental (acoustic and electroacoustic) to electronic music, from modernity to postmodernity. These cases come from two seemingly different spheres of culture, yet they are both captured at a similar mediatory state of flux. First a domestic example: in his excellent book on the last musicians of the Polish countryside, Andrzej Bieńkowski (2012) notes such an observation concerning the process of modernization of folk music through the appearance of "town" instruments, and later also electric ones: "The fiddle player no longer improvises, . . . but follows the accordionist. The connection between singing and music, which has been the foundation of the musician's education and repertoire, is slowly torn apart. The musicians detach themselves from the wedding guests: they just get up for the dances. This becomes glaringly apparent when the musicians are connected to an amplifier; how to carry out a calland-response with a loudspeaker?" (p. 31). So this is a rather characteristic example of cultural "progress" - the modernization of instruments which results in a change in repertoire and irreversible transformation of a communicative situation. However, we are fully aware that this process, which had already started in Poland before WWII, did not end with turning to electric instruments. Bieńkowski also realizes this, describing the dilemmas he faced during the recordings he made at the end of the previous century: "Is folk music played by bands with fiddles, or is a button or piano accordion enough? If the latter, why not a Yamaha synthesizer, which plays a mazurek with an electronic drum machine (with computer software simulating a fiddle sound - and I have heard such music)?" (p. 16) Here is the new universum of folk music: dominated by the world of electronic simulations of what we know well. The second example comes from a fascinating book by Christopher Partridge, a professor of religious studies at Lancaster University, who writes about the evolution of Jamaican dub which occurred subsequently in two culturesCaribbean and European — and postulates a close connection between the migration of this music from Jamaica to Europe with departure from electroacoustic recordings of reggae in favor of involving "pure electronics"- music which comes from electronically synthesized sound. ${ }^{5}$ In Partridge's (2010, p. XIII) opinion, this was also the transition into the

\footnotetext{
${ }^{5}$ To illustrate this transition, it is best to juxtapose specific musical realizations, such as the classical Jamaican albums Dub from the Roots (1975) by King Tubby or East of the River Nile (1977) by Augustus Pablo, with European albums of dub electronic music: I (1998) by Pole or Rhythm \& Sound (2001) by Moritz von Oswald. German studios and record labels (Basic Channel) appear here to be perfectly designed, fully electronic virtual simulations of famous Jamaican studios such as Channel One and The Black Ark.
} 
sphere of cultural (and musical) postmodernism. In both cases, the step into postmodernism was made through moving from the modernist tendency of elaborating (electrification) of musical instruments to the electronic simulation of natural and acoustic sounds.

In order to wrap up these speculations, we may dare to draw the following conclusion: modernity, with its accompanying optimistic mythos of civilizational progress, was directly striving to modernize what it had found, evoking the principle of cultural evolution. In terms of the culture of sound it, was represented by the discoveries and experiments of the musical avant-garde, which can be successfully exemplified by concepts such as electroacoustic music and its technical attributes: processing and electric ${ }^{6}$ amplification of a sound signal coming from an acoustic (instrumental) source. Its products included electric guitar and the procedure of elaborating instruments, that is, modification of (sound) reality through the application of available techniques (see Brzostek, 2012). This of course needed an a priori assumption that there is a reality subjected to the process of modernization (i.e., one in which progress or evolution occurs). Creative inventions of modernism also included new (nontraditional) instruments built by creators such as Harry Partch and Moondog (Louis Hardin); also, anti-instruments (the famous Dadaist intonarumori noise machines) and even the non-instruments proposed by Cage (tables, chairs, brake drums). All of them modernized the already existing set of instruments, or they expanded the sphere of acoustic sound sources with tools (previously) considered to be outside the domain of music.

The breakthrough occurs with the discovery of electronic sound synthesis; if we mention the memorable performances of such compositions as One for violin by Nam June Paik and Piano Activities by Philip Corner, its symbolic portent could have been the (anti-)aesthetic acts of destroying traditional musical instruments used by certain neo-Dadaist creators with connections to the Fluxus circle. From then on the postmodernist order of creation will continue through a peculiar lack of instrument, symbolic or actual, signifying that sound is obtained from an absolute void marked precisely by the absence of instruments; examples of this are the famous concept of the „no-input mixing board” by Toshimaru Nakamura, i.e., using instead of an instrument a mixing console without an external sound source, or the less known tapeless recorder by Sergio Merce. This is the way in which the postmodern universum of simulations is established, where natural sounds are copied and reproduced by (the force of) technology, and where the electronic synthesis of impossible sounds or imitation of acoustic sounds occur, leading toa kind of "virtual sound reality." Its patron saints are Pierre Schaeffer, Bernard Parmegiani and Luc Ferrari, and it is purely the realm of sound objects and acousmatic sounds, which make the simulation of the real indistinguishable from reality itself. Thus the structuralist (or maybe poststructuralist?) sonoristic triangle reveals a postmodernist breakthrough in sound culture.

\footnotetext{
${ }^{6}$ Electricity is undoubtedly among the elements of the modernist imaginarium associated with the myth of progress which create the greatest impact

${ }^{7}$ Acousmatic sound objects fill, e.g., the famous album of Bernard Parmegiani De natura sonorum (1975), and the (nonetheless acousmatic) ,impossible sounds" can be heard for example in the collection of miniatures by Arne Nordheim Dodeka (2003).
} 


\section{Bibliography}

Baudrillard, J. (1988). Simulacra and simulations. (P. Foss, P. Patton, \& P. Beitchman, Trans.). In M. Poster (Ed.), Jean Baudrillard: Selected writings. Stanford, CA: Stanford University Press.

Baudrillard, J. (1991). Simulacra and science fiction. (A. B. Evans, Trans.). Science Fiction Studies, 55(18), 3. Retrieved from http://www.depauw.edu/sfs/backissues/55/baudrillard55art.htm 1

Bieńskowski, A. (2012). Ostatni wiejscy muzykanci. Warszawa: Wydawnictwo Muzyka Odnaleziona.

Brzostek, D. (2011). Impossible sounds and the virtuoso's identity. Fragile, 4(14), 69-73.

Brzostek, D. (2012). To nie jest trąbka: Przyczynek do fenomenologii instrumentów preparowanych. Fragile, 1(15), 50-54.

Godøy, R. I. (2008). Pour un théorie musicale fondée sur les objets sonores. In D. Terrugi (Ed.), Pierre Schaeffer: Portraits polychromes. Paris, France: Institut National de L'Audiovisuel.

Jameson, F. (1997). Postmodernism, or the cultural logic of late capitalism. Durham, NC: Duke University Press.

Lem, S. (1984). Summa technologiae. Lublin, Poland: Wydawnictwo Lubelskie.

Lévi-Strauss, C. (2008). The culinary triangle. In C. Counihan, \& P. van Esterijk (Eds.), Food and culture: A reader (pp. 37-43). New York, NY: Routledge.

Lyotard, J.-F. (1984). Answering the question: What is postmodernism? (R. Durand, Trans.). In J.-F. Lyotard, The postmodern condition: A report on knowledge. Manchester, UK: Manchester University Press.

Murch, W. (1994). Foreword. In M. Chion, Audio-vision: Sound on screen. (C. Gorbman, Trans.). New York, NY: Columbia University Press.

Partridge, C. (2010). Dub in Babylon: Understanding the evolution and significance of dub reggae in Jamaica and Britain from King Tubby to post-punk. London, UK: Equinox.

Schaeffer, B. (1987). Maty informator muzyki XX wieku. Kraków, Poland: Polskie Wydawnictwo Muzyczne. (Translations of Polish-language sources provided by the author.)

Schaeffer, P. (2004). Acousmatics. (D. W. Smith, Trans.). In C. Cox \& D. Warner (Eds.), Audio culture: Readings in modern music (pp. 77-78). New York, Ny: Bloomsbury Academic

\section{Music albums:}

Augustus Pablo (1977). East of the river Nile.

Bernard Parmegiani (1975). De natura sonorum.

King Tubby (1975). Dub from the roots.

Moritz von Oswald (2001). Rhythm \& sound.

Pole (1998). I. 